\title{
COMUNIDADES RECEPTORAS LOCAIS E COMUNIDADES DE TURISTAS: REDIMENSIONANDO RESPONSABILIDADES PARA UM TURISMO SUSTENTÁVEL
}

\author{
A na Lúda Camphora Pacheo**
}

\begin{abstract}
A bstract
The possibility of redefining the principles that underlie the models of temporary co-existence - where the civilized and the exotic, the dominating and the dominated, the global and the local meet with one another - offers a panorama for reflecting on the social dimension of the sustainability of tourism. Examining the crisis of modernity - tied as it is to the dichotomy that views nature and society as isolated, airtight categories - helps to clarify further the hybrid conditions that disturb the dynamics of the interaction between individual and collective identities.
\end{abstract}

Keywords: Sustainable Tourism; Sustainable Development; Social Responsibility; Tourist; Community.

Este ensaio tem o objetivo de provocar reflexões sobre possíveis alternativas para o enfoque das relações entre as comunidades locais dos destinos turísticos e as comunidades de turistas. A visibilidade deste fenômeno, cuja complexidade tem sido parcialmente discutida, lança o desafio de abordar a dimensão psicossocial do turismo sustentável, entendido, segundo IRVING (2001) como um modelo de desenvolvimento estratégico, que implica na mobilização comunitária e no desejo de enfocar o ambiente como um bem coletivo a ser preservado em suas dimensões econômica, ecológica e social.

O turismo incita à distinção de, pelo menos, dois tipos de sujeito em interação: o que, por sua mobilidade, iria ao encontro de um outro que, na maioria das vezes, se encontraria restringido à sua condição local. Os efeitos dessas relações, que incidem sobre as comunidades anfitriãs e sobre a qualidade da experiência turística, traduzem uma dimensão diversificada e dinâmica do turismo sustentável. Entretanto, os componentes sociais da atividade, freqüentemente enfocados a partir de uma abordagem dicotômica, identificariam as comunidades locais e os turistas como categorias contrárias, facilitando a percepção de conflitos entre os interesses e valores distintos envolvidos nessas relações. Essa perspectiva também pode dificultar o entendimento sobre possíveis laços, influências e interações, gerados a partir das diversas competências e ações constituídas nesse cenário.

$\mathrm{O}$ confronto de diferenças gerado no encontro entre essas identidades é, com freqüência, caracterizado como conflito e desequilíbrio: comunidades locais, restritas a seus espaços e tempos, submetidas a um isolamento relativo, com estilos de vida onde predominariam atividades de aprovisionamento versus comunidades de turistas, procedentes de contextos socioculturais mais amplos, integradas em uma sociedade urbano-industrial global. Esta oposição, que parece não estar encontrando respostas e soluções satisfatórias para problemas que se multiplicam nas condições diversificadas da atualidade, parece simplificar o debate sobre a dimensão social da sustentabilidade turística encobrindo, possivelmente, formas mais complexas de interação.

A oposição entre comunidades receptoras locais e comunidades de turistas projeta duas outras perspectivas. A primeira, diz respeito ao sistema de representação de mundo que resultou do projeto moderno, baseado na dicotomia entre sociedade e natureza, que pode ser redimensionada para melhorar o entendimento sobre a extensão dos interesses simultaneamente naturais e sociais que conduzem à sustentabilidade turística. A segunda, que corresponde a um efeito da primeira, permite abordar a ruptura que definiu a relação da sociedade ocidental moderna com todas as "outras", consideradas pré-modernas, primitivas ou tradicionais.

Essas questões emergem a partir da insuficiência dos dispositivos modernos de isolamento e ordenamento diante da tarefa de dar conta da grande variedade de categorias, interações e modos de reagrupamento, assim como de técnicas, papéis e instituições, na atualidade. O deslocamento do foco de problematização sugere uma menor preocupação com a delimitação de categorias e fronteiras - moderno/tradicional, artesanal/industrial, natural/social/local/global -, e maior atenção com relação à pluralidade e à dinâmica das interações, que se revelariam como condições significativas da atualidade.

Interesses simultaneamente naturais e sociais, mobilizados a partir de uma perspectiva de sustentabilidade, implicam o reconhecimento da participação prioritária de atores historicamente excluídos dos cenários de decisão - as comunidades locais e o meio ambiente. Esses objetivos que, segundo IRVING (2002), ${ }^{1}$ pressupõem responsabilidade social e ética, coparticipação e avaliação do custo-benefício por todos aqueles que estejam envolvidos, sejam ou não considerados beneficiários, conduziriam a um desenvolvimento controlado, qualitativo, a longo prazo, com controle local, conforme descreve SWARBROOKE (2000). ${ }^{2}$ Os resultados apontam para uma reavaliação das expectativas dirigidas pelo modelo de desenvolvimento que associou planejamento turístico à descaracterização cultural, exclusão econômica das populações locais e impactos ambientais negativos. Em políticas de planejamento, decisão e administração, seriam reavaliadas, sobretudo, as desarticulações entre fatores econômicos, sociais, culturais e ambientais. Com relação a tal propósito, diversos autores enfatizam, sob pontos de vistas distintos, as Ciências Humanas e Sociais como eixo essencial para tematizar a sustentabilidade: 
Os fatores humanos são as forças propulsoras chave neste intrincado conjunto de relações e exercem influência direta nas mudanças a nível mundial. Em conseqüência, é indispensável o estudo das dimensões humanas das causas e conseqüências das mudanças ecológicas e das formas de desenvolvimento mais sustentáveis. (AGENDA 21, (1992). ${ }^{3}$...o reconhecimento das questões ambientais como sócio-a mbientais tem despertado nos gestores, parceiros e estudiosos a necessidade de recorrerem às Ciências Sociais para buscar maior compreensão dos fenômenos e formas de intervenção mais adequadas. (CERQUEIRA (1997). ${ }^{4}$ Onde quer que olhemos - energia nuclear, resíduos tóxicos, pesticidas, poluição atmosférica, qualidade da água vemos exemplos de nosso fracasso em apreender as implicações sociais do conhecimento científico que possuímos e os custos transferidos ao meio a mbiente." (REDCLIFT, (2001). ${ }^{5}$ A concepção de desenvolvimento sustentá vel implica um novo paradigma do pensar as sociedades humanas segundo uma nova ética de democratização de oportunidades e justiça social, percepção das diferenças como elemento norteador de planejamento, compreensão da dinâmica de códigos e valores culturais e compromisso global com a conservação de recursos naturais. (IRVING (2002). ${ }^{6}$

A dimensão social da sustentabilidade é tomada como uma das bases para o planejamento, a promoção e o gerenciamento de atividades, nas diretrizes nacionais formuladas para o desenvolvimento do segmento ecoturístico (EMBRATUR/IBAMA, (1994). ${ }^{7}$ O envolvimento ativo das comunidades receptoras dos locais de destino como "atores importantíssimos", desde o estágio preliminar de planejamento, até a implementação e a operacionalização das ações, é uma das premissas desse segmento em expansão do setor turístico. Também foi destacada a necessidade de orientar uma conduta adequada, por parte dos turistas, com relação aos atrativos naturais e culturais e, em especial, com relação ao seu comportamento junto às comunidades locais. Entre os inúmeros obstáculos ao planejamento sustentável do segmento, foram identificados problemas associados ao "comportamento inadequado do turista" e à "participação comunitária deficiente"; a respeito dos turistas, foram apontadas a falta de orientação a respeito do lazer de natureza, conscientização e conhecimento insuficientes, pouca orientação e marketing inadequado. Com relação às comunidades receptoras, foram identificados problemas relacionados ao seu despreparo, falta de acesso a informações, incompatibilidade entre os interesses locais e a atividade, exclusão dos processos de decisão, preconceito contra o turismo e retorno financeiro insuficiente. ${ }^{8}$

O reconhecimento de que o turismo põe em contato diferentes culturas e estilos de vida, de forma direta, espontânea e imediata, revela uma dimensão da atividade, entendida como uma ação a serviço da paz e da união entre os povos. A necessidade de integrar princípios de respeito e compreensão, nas relações entre comunidades locais e turistas, é amplamente justificada pelo Código Ético Mundial para o Turismo. ${ }^{9}$ Nos objetivos sociais dimensionados no texto do Código, podem ser destacados o entendimento e o respeito entre homens e sociedades como responsabilidade comum, tanto dos turistas como das comunidades receptoras, através do reconhecimento da diversidade social e cultural diante de peculiaridades, tradições, crenças e hábitos. Essa compreensão pode ser um fator de hospitalidade das comunidade locais, além de garantir uma maior segurança para o turista, assegurada pela informação acerca dos regulamentos locais e dos riscos potenciais gerados pela atividade para as localidades turísticas. Uma educação individual e coletiva, dirigida para o reconhecimento e a percepção da diversidade de identidades e direitos específicos, em especial daquelas minorias mais vulneráveis, constituiria um reforço aos valores sociais e culturais do turismo.

A participação privilegiada do meio ambiente e das comunidades locais, como atores nas decisões e nos direitos relacionados à sustentabilidade turística, aponta para a revisão do modelo característico da modernidade: a ruptura entre sociedade e natureza, categorias tratadas no interior de campos de conhecimentos distintos. A impossibilidade de enxergar, na atualidade, uma fronteira que delimite propriedades, competências e atribuições específicas a essas categorias indica a necessidade de redimensionar a visão de mundo que dirigiu o pensamento moderno. Ao questionar dois paradigmas centrais da modernidade, LATOUR (1994) ${ }^{10}$ focaliza a ruptura entre natureza e sociedade e, como uma de suas conseqüências, a "grande divisão" que isolou a sociedade ocidental das outras, denominadas primitivas ou pré-modernas. Seu enfoque propõe uma antropologia do mundo moderno, capaz de abrigar, simetricamente, humanos e não-humanos, ${ }^{11}$ desde que nos sentimos incapazes de viver a partir de uma perspectiva prisioneira dos domínios da natureza ou das organizações sociais.

Essa visão de mundo dicotômica caracteriza a constituição moderna, que deflagrou a evolução da civilização ocidental. A modernidade corresponde à ruptura com um passado arcaico, estável, em cuja "desordem" natureza e sociedade formariam um “tecido inteiriço" (LATOUR (1994). ${ }^{12}$ Romper com esta indistinção foi o objetivo que mobilizou o esforço moderno, através de um acordo firmado a partir da divisão de poderes que garantiu domínios específicos aos fatos naturais - exclusivamente representados pela ciência, constituída sem nenhum tipo de influência social -, e aos fenômenos sociais - completamente legitimados por forças sociais. Tal isolamento eliminou toda a possibilidade de laços e influências entre as duas categorias, produzindo a assimetria entre sociedade e natureza, humanos e não-humanos.

A "grande divisão" entre a sociedade moderna e todas as outras que não se enquadrariam em sua visão de mundo constitui uma outra oposição determinada por esta ruptura. A sociedade que se constituiu a partir do isolamento com relação à natureza tomou a ciência e as técnicas modernas como seu maior trunfo para garantir o predomínio com relação àquelas consideradas primitivas, tradicionais ou pré-modernas. A racionalidade e a eficiência técnica operaram o ordenamento e a classificação de tudo o que pareceu desorganizado e irracional, para romper com a confusão entre crenças e fatos, mitos e leis universais e combater as misturas próprias do mundo incivilizado. O acesso privilegiado a uma natureza universal produziu a diferença da sociedade moderna com relação às outras, portadoras de uma visão limitada, relativa, contingente, local; suas crenças, técnicas e domínios se tornaram objeto das etnociências, considerados como aspectos restritos e parciais de uma representação monista do mundo.

Nos registros etnográficos sobre os encontros entre ocidentais e povos primitivos, GEERTZ (2001) $)^{13}$ percebeu uma 'profunda descontinuidade cultural', reforçada pela crença ocidental em sua própria missão de colonizar a natureza e povos, essencialmente movidos pelas paixões expressas por suas cosmologias, ritos e sacrifícios. A racionalidade ocidental operou o modelo daqueles que decidem pelas ações sobre outros que são “...objetos do saber e em nome dos quais se tomam decisões." (GEERTZ (2001). ${ }^{14}$ 
O propósito de delimitar identidades culturais distintas sugere uma forma de defesa legítima contra o projeto de assimilação e dissolução da alteridade, em nome da unidade do Estado moderno: consolidou os limites e enfatizou o poder das fronteiras contra a circulação e o inter-câmbio, como garantia de preservação e autonomia da identidade cultural. Mas o esforço de honrar a alteridade atendeu ao objetivo moderno de encaixe dos diferentes em suas próprias categorias, segundo o melhor estilo de engenharia social, dirigida pelo sonho de pureza. Uma comunidade seria purificada na medida em que demarcasse sua diferença com relação a tudo o que se distingue daquilo que compartilha em seu interior (BAUMAN (1999). ${ }^{15}$

Reflexos dessa visão de mundo, no contexto socioambiental brasileiro, foram identificados por DIEGUES (1996) ${ }^{16}$ na política de conservação dos parques nacionais que inspirada na estratégia ocidental de proteção à natureza, pretendeu assegurar o isolamento de dois mundos - a civilização moderna e a natureza selvagem. A presença de populações nessas áreas era, assim, incompatível com o objetivo de preservar uma natureza isolada do contexto das ações e valores humanos. Para o autor, esse modelo, que corresponde ao 'neomito' de uma natureza pura, orientou o manejo das áreas de conservação onde, além da biodiversidade, habitam as denominadas populações tradicionais - caiçaras, vargeiros, pantaneiros, ribeirinhos, pescadores e jangadeiros, habitantes de diferentes regiões do território brasileiro, com estilos de vida basicamente orientados por atividades de aprovisionamento, com baixa acumulação de capital e predomínio das relações familiares e comunais.

Como um objeto submetido às conveniências da sociedade moderna, o controle da natureza foi uma responsabilidade atribuída a entidades preservacionistas públicas e privadas. Esse modelo conduziu à exclusão dessas populações, à anulação de seus direitos, saberes e técnicas, subordinados à afirmação do saber científico e das técnicas modernas. O projeto do turismo de natureza seria, para DIEGUES, ${ }^{17}$ uma conseqüência natural dessa estratégia, inspirada no modelo do parque nacional americano que, já em 1918 , contava com estradas asfaltadas e infra-estrutura para receber visitantes motorizados (USIS, 1991). 18 "Espaços públicos" criados e administrados para cumprir um objetivo nacional, as áreas de preservação beneficiariam majoritariamente os interesses das populações urbanas, deslegitimando os "espaços comunitários", geridos por elementos simbólicos e organizações locais específicos:

Na verdade, o que está implícito é que estas deveriam 'sacrificar-se' para dotar as populações urbano-industriais de espaços naturais, de lazer e 'contato com a natureza selvagem'. Ou ainda, segundo uma visão mais moderna dos objetivos das áreas naturais protegidas de uso restrito - proteger a biodiversidade. (DIEGUES ). ${ }^{19}$

A possibilidade de mediar interesses naturais e sociais pode caracterizar melhor a perspectiva de sustentabilidade; uma lógica capaz de apropriar a emergência dos cenários híbridos, ao expressar interesses e valores que não compreendem sociedade e natureza como entidades opostas e isoladas. A dificuldade, cada vez maior, de reconhecer os fatos da natureza e os valores sociais como categorias isoladas arbitrariamente, parece ser efeito do desequilíbrio provocado pelos mecanismos de isolamento e purificação que produziram domínios e interesses próprios do sistema de representação de mundo moderno. Na prática, a modernidade não foi capaz de dar conta da proliferação de híbridos, entidades simultaneamente sociais e naturais (LATOUR (1994). ${ }^{20}$ A necessidade de dar conta do trabalho cada vez mais minucioso de classificar, incluir e excluir, produzir autonomias territoriais, correspondeu ao objetivo de produzir um mundo de modelos memorizáveis, estáveis e previsíveis. Mas a crescente instabilidade desses modelos, na atualidade, percebida a partir dos deslocamentos de categorias, da fluidez das fronteiras, de incerteza e contingência, seria uma conseqüência do fracasso desse projeto (BAUMAN, 1999). ${ }^{21}$

No momento em que, em nossa própria constituição individual, na camada de ozônio ou no turismo sustentável, ocorrem múltiplas articulações que não poderiam ser entendidas como efeito de relações dicotômicas, não parece ser mais possível viver em um mundo assimétrico - sob os domínios de uma natureza universal ou de representações sociais.

Essas condições apontam para uma diferença fundamental com relação a expectativas quanto aos efeitos do desenvolvimento: enquanto na modernidade, o progresso consistiu na tarefa de ordenar os sujeitos das ações e seus objetos, impor ordem ao caos e à indeterminação, outros mecanismos, visíveis da atualidade, apontariam para uma maior intimidade entre humanos e nãohumanos, que estariam mais confundidos no futuro do que no passado (LATOUR (2001). ${ }^{22}$ Dessa forma, ao contrário do que o projeto de purificação moderno previu, a definição de civilização consistiria em um número cada vez maior de hibridizações. Nessas condições, o propósito de garantir identidades emolduradas e delimitadas, que dirigiu o conceito moderno de diversidade cultural, não se aplicaria à dinâmica dos contatos e da superposição de mundos tão diferentes, na atualidade. Quando 'nativos' se tornam cidadãos - com autonomia, identidade e direitos -, outras formas de desigualdade, conflitos de poder, pressões e influências, emergem de interações e intercâmbios múltiplos (GEERTZ). ${ }^{23}$

Quando defende a importância da presença das comunidades tradicionais no interior das áreas de conservação, DIEGUES ${ }^{24}$ identifica indefinições conceituais para o entendimento da noção de "comunidade tradicional" e falta de consenso quanto à sustentabilidade de suas formas de uso dos recursos naturais. Dois níveis de interação com outras culturas, pelo menos, podem ser considerados para entender a noção de comunidade tradicional: as tribos indígenas, ou "povos da natureza", seriam comunidades identificadas por sua simbiose com os ecossistemas, enquanto as "culturas tradicionais" ou "povos da biosfera", seriam comunidades com maior comunicação com a civilização urbano-industrial.

A dimensão do território brasileiro e a consolidação de um país cada vez mais urbano, a partir da segunda metade do século XX, são fatores determinantes de um isolamento relativo dessas populações. Muitas permaneceram nas áreas florestais litorâneas remanescentes que, no passado, foram ocupadas pelos sistemas de monocultura colonial, que se transformaram, a partir da década de 30, em áreas protegidas. Os possíveis impactos gerados por essas formas "comunitárias" de apropriação dos recursos naturais, são avaliados sob uma perspectiva sócio-econômica: pequena produção mercantil como agricultura, extrativismo, atividades de subsistência e trabalho assalariado ocasional (DIEGUES). ${ }^{25}$ De fato, suas formas de produção estiveram sempre associadas a contextos escravocratas, feudais ou capitalistas, e à baixa acumulação de capital, dificultando o surgimento de novas classes sociais. Além disso, o baixo impacto de suas tecnologias e a baixa densidade populacional favoreceriam a renovação dos recursos 
naturais. Mas desorganizações produzidas pelas relações com a "sociedade global capitalista", provocariam desestruturações nos sistemas de produção dessas populações; essa dependência afetaria, no contexto atual, suas condições econômica, ecológica e sociocultural.

Entre os impactos gerados pelos grandes projetos de desenvolvimento econômico e social, o turismo seria um fator a mais para a desestruturação dos espaços comunitários, pela sua usurpação em benefício dos interesses das populações urbanas. A desorganização das relações entre essas comunidades e a natureza seria uma conseqüência da sua dependência quanto ao sistema capitalista.

Antagonismos que regulam as relações entre o local e o global podem ser reexaminados. A distinção intrínseca entre o local e o global, sendo um definido a partir do que se atribui ao outro, corresponde ao recurso conceitual de utilizar extremos que se definem e se opõem. Dessa forma, as variações entre local e global resultam do dimensionamento que atribuiu ao Ocidente a condição universal, ou global, em oposição à condição circunstancial e relativa do local (LATOUR (1994). ${ }^{26}$

No contexto do planejamento turístico, 'base local' compreende:

...um espaço geográfico delimitado por características intrínsecas e comuns físicoterritoriais e sócio-culturais e, por isso, associa-se ao desenvolvimento regional em qualquer uma de suas múltiplas dimensões. Engloba e explica também a participação engajada e efetiva da população residente nas iniciativas de desenvolvimento, no processo de produção de bens e serviços e na gestão de um complexo político-empresarial. (BENI (2001). ${ }^{27}$

Ao se referir ao "saber local", sob uma perspectiva antropológica, GEERTZ ${ }^{28}$ enfatiza que "local" é um termo relativo, e que é preciso um cuidado especial para aplicar qualquer tipo de oposição entre o local e o universal. Em oposição ao particularismo e à contingência local, de forte interação pessoal, o global se define por sua condição universal, resultante dos efeitos de disseminação sobre o espaço e o tempo, determinados pela ampla escala de suas redes e conexões. Diferenças geradas, exclusivamente, pela dimensão e número de conexões entre humanos e não-humanos, foram associadas a uma ordem universal global.

Os grandes símbolos modernos de movimento, fluidez, velocidade e descontextualização convergem sobre fenômenos e equipamentos turísticos - aviões, aeroportos, rodovias; nesse cenário psicossocial, escalas servem como acampamentos e não como domicílio, e apenas raízes superficiais são lançadas pelos turistas. Com relação às pessoas do lugar - simples zeladoras das estalagens no meio do percurso, como descreve BAUMAN -, eles apenas cruzam ou tropeçam, em contatos contingentes. A esse turista caberia o papel de executar as regras de um jogo globalizado: "Antes e acima de tudo, eles realizam a façanha de não pertencer ao lugar que podem estar visitando: é deles o milagre de estar dentro e fora do lugar ao mesmo tempo."29

Uma redefinição dos princípios hierárquicos modernos atribuídos à diversidade cultural sugere que mecanismos de dominação podem dar lugar a mecanismos de emancipação. Nem superioridade, baseada no domínio de uma verdade - e direito -, superior, e nem simplesmente tolerância, parecem sustentar uma coexistência, mesmo temporária, em um lugar de destino comum a comunidades receptoras e a comunidades de turistas. O encontro entre o civilizado e o exótico, o dominante e o dominado, o local e o global, se converteria no encontro entre o "outro" emancipado e aquele que, na atualidade, viveria uma existência desprovida de certeza. Para BAUMAN, esse redimensionamento da diversidade social torna-se possível através da solidariedade, desde que não pode "...derivar sua confiança de nada sequer remotamente sólido e portanto confortador como as estruturas sociais, as leis da história ou o destino das nações e raças, de que os projetos modernos extaríram seu otimismo, autoconfiança e determinação."30 Uma alternativa à definição arbitrária de papéis estabelecidos a priori, é apontada na leitura das recomendações da Agenda 21,31 para alcançar uma autêntica participação social em direção ao desenvolvimento sustentável. As medidas voltadas para o fortalecimento do papel dos grupos principais não partem da definição antecipada de categorias; a necessidade de reconhecer a participação de outros atores nas decisões envolve, igualmente, todas as pessoas, grupos e organizações interessadas, em especial aqueles diretamente afetados pelas ações. Todos têm, também, a mesma necessidade de acesso a informações sobre as medidas de desenvolvimento e de proteção ao meio ambiente. Como definição operacional das áreas de programa da Agenda 21 , foram identificados como grupos principais: a mulher, a infância e a juventude, populações indígenas, organizações não governamentais, autoridades locais, trabalhadores e seus sindicatos, comércio e indústria, comunidade científica e tecnológica e agricultores. Essa perspectiva simétrica, não fundada em antagonismos, parece indicar que novas formas de participação também implicam uma reavaliação da lógica dos procedimentos necessários ao desenvolvimento sustentável.

O reconhecimento de semelhanças e diferenças, por si só, não determina a imposição arbitrária de fronteiras - que obscureceriam a percepção e o entendimento de toda a extensão das relações entre identidades individuais e coletivas distintas. Outras bases de avaliação podem ser mais compatíveis para enfocar os componentes psicossociais da sustentabilidade turística. O contexto brasileiro impõe como desafio incluir aqueles segmentos sociais submetidos às pressões de um modelo socioeconômico centralizado, que jamais considerou qualquer expressão de diversidade local, seja de caráter cultural ou ambiental. O modelo participativo, considerado como premissa para o reconhecimento e a valorização da singularidade do imaginário e dos saberes locais, aponta para processos que, uma vez deflagrados, podem se configurar de forma irreversível. A participação comunitária, que segundo IRVING (2002), ${ }^{32}$ envolve o acesso à educação e a informações para ações sociais conscientes, integra o prazer de compartilhar a medidas eficientes para a obtenção de resultados. Mas não existem mecanismos "pré-fabricados" para essa tarefa, que implica um amadurecimento social gradativo em direção à capacitação e a uma postura política responsável.

O reconhecimento da crise que afetou a visão de mundo moderna assinala, assim, o propósito de pensar sociedade e natureza fora do panorama limitado pela dicotomia. Ao reconhecer a impossibilidade de pensar qualquer estrutura social que não incorpore a mistura crescente de humanos e não-humanos, LATOUR $(2001)^{33}$ propõe uma abordagem melhor habilitada para reconhecer as múltiplas articulações possíveis entre ações, competências e funções que não podem ser identificadas por atributos assimétricos, exclusivamente situados em categorias delimitadas como sociais ou naturais. Comunidades distintas correspondem, portanto, a 
distintas formas de mobilizar entidades humanas, naturais e técnicas.

Com relação ao contexto mais amplo do turismo sustentável, a extensão dessas articulações seria apreciada na ênfase dada pelo secretáriogeral da Organização Mundial do Turismo, Francesco Frangialli, à necessidade de utilizar tecnologias na conservação dos recursos naturais, por ocasião da escolha do tema 'Tecnologia e Natureza', para o Dia Mundial do Turismo de $2000 .{ }^{34}$ Articular natureza, sociedade e técnica atende a um turismo sustentável, essencialmente beneficiado pelas novas tecnologias, sejam elas aplicadas à mobilidade, ao conforto, à teleinformática ou à segurança ambiental.

Com relação aos intercâmbios entre identidades individuais e coletivas distintas, potencializadas pela atividade, LATOUR $(1994)^{35}$ propõe restaurar a simetria entre a sociedade ocidental e todas as outras, desde que seja possível entender a diferença entre o extenso campo das ciências e das técnicas modernas e o dos saberes, poderes e peculiaridades das outras sociedades como variações de tamanho e de extensão; e, portanto, relativizar a crença no caráter universal atribuído à sociedade moderna. Desfeita a assimetria e, também, a distinção entre as esferas social e material - que corresponde aos fatos da natureza e às técnicas -, a distribuição de competências e responsabilidades entre todos os atores, humanos e não-humanos, pode conduzir a um legítimo exercício de cidadania, orientado para uma 'ecologia política'.

A esse respeito, vale ouvir a impressão de Bruno Latour sobre esses desdobramentos, para uma maior visibilidade sobre as novas dinâmicas e articulações que parecem incidir, especialmente, sobre as bases sociais que permitem dimensionar a sustentabilidade turística:

Advogados, ativistas, ecologistas, empresários e filósofos políticos sugerem seriamente agora, no contexto de nossa crise ecológica, que se concedam a não-humanos alguns direitos e mesmo uma condição jurídica. Não faz muito tempo, contemplar o céu significava refletir sobre a matéria ou a natureza. Hoje, vemo-nos em presença de uma confusão sociopolítica, pois o esgotamento da camada de ozônio provoca uma controvérsia científica, uma disputa política entre o Norte e o Sul, bem como importantes mudanças estratégicas na indústria. A representação política de nãohumanos parece atualmente não apenas plausível como necessária, embora fosse considerada há poucos anos ridícula ou indecente. Costumávamos zombar dos povos primitivos por acreditarem que uma desordem na sociedade, uma poluição, a meaçaria a ordem natural. Já não nos rimos com tanto gosto, pois deixamos de usar a erosóis com medo de que o céu desabe sobre nossas cabeças. Como os 'primitivos', tememos a poluição causada por nossa negligência - o que significa, é claro, que nem 'eles' nem 'nós' fomos alguma vez primitivos (LATOUR (2001)..$^{36}$

Notas

1 IRVING, M.A. Participação: questão central na sustentabilidade de projetos de desenvolvimento. In: IRVING, M. A; AZEVEDO, L. Turismo, o desafio da sustentabilidade. São Paulo: Ed. Futura, 2002.

2 SWARBROOKE, J. Turismo sustentável: conceitos e impacto ambiental. São Paulo: Ed. Aleph, 2000.

3 CONFERENCIA DE LAS NACIONES UNIDAS SOBRE EL MEDIO AMBIENTE Y EL DESARROLO, Rio de Janeiro, 1992. Agenda 21.p. 16-17.

4 CERQUEIRA, M.C. Gestão ambiental na realidade da Rio plus 5 a Caruaru plus 1. Subsídios INESC, Brasília, v. 5, n. 33, 1997. p. 18.

5 REDCLIFT, M. Feitos à nossa imagem: o meio ambiente e a sociedade como discurso global. In: ARIZPE, L. As dimensões culturais da transformação global. Brasília: UNESCO, 2001.p. 234-235.

6 IRVING, M.A. (2002) op. cit., p. 35.

7 EMBRATUR. Diretrizes para uma política nacional de Ecoturismo. Brasília, Ibama, 1994.

8 Para maiores detalhes, ver gráfico 'Matriz de Problemas' (EMBRATUR. (1994) op. cit.

9 CÓDIGO Ético Mundial para o Turismo, em http://www.ecotourism.og/textfiles/ board-062001.html em 20/03/2002.

10 LATOUR, B. Jamais fomos modernos. Rio de Janeiro: Ed. 34, 1994.

11 Quando identifica o acordo moderno, que teria isolado arbitrariamente natureza e sociedade como pólos opostos e incomunicáveis, Bruno Latour propõe a noção de 'coletivo' - que designa entidades simultaneamente naturais e sociais, que não se enquadram em nenhuma das duas categorias. Coletivos são constituídos por humanos e não-humanos, que não seriam mais considerados como simples objetos, e, assim, designando os agentes naturais e técnicos (LATOUR (1994) op. cit.

12 LATOUR, B. (1994) op. cit.

13 GEERTZ, C. Nova luz sobre a antropologia. Rio de Janeiro: Jorge Zahar, 2001.

14 Id. ibid., p. 91.

15 BAUMAN, Z. Modernidade e ambivalência. Rio de Janeiro: Jorge Zahar, 1999.

16 DIEGUES, A. C. O mito moderno da natureza intocada. São Paulo: Hucitec, 1996.

17 Id. ibid.

18 USIS. Serviço de Parques Nacionais: uma história. Brasília: Serviço de Divulgação e Relações Culturais dos EUA, 1991.

19 DIEGUES, A. C. (1996) op. cit., p. 66.

20 LATOUR, B. (1994) op. cit.

21 BAUMAN, Z. (1999) op. cit.

22 LATOUR, B. A esperança de pandora. São Paulo: EDUSC, 2001.

23 GEERTZ, C. (2001) op. cit.

24 DIEGUES, A. C. (1996) op. cit.

25 Id. ibid.

26 LATOUR, B. (1994) op. cit.

27 BENI, M. C. Política regional sustentável em clusters de turismo: a realidade brasileira. Boletim de Turismo e Administração 
Hoteleira, São Paulo, n. 2, out., 2001.p. 60.

28 GEERTZ, C. (2001) op. cit.

29 BAUMAN, Z. (1999) op. cit., p. 114.

30 Id. ibid. p. 271.

31 CONFERENCIA DE LAS NACIONES UNIDAS SOBRE EL MEDIO AMBIENTE Y EL DESARROLO. (1992) op. cit. 32 IRVING, M.A. (2002) op. cit.

33 LATOUR, B. (2001) op. cit.

34 Comunicação sobre o Dia Mundial do Turismo em http://www.ecotourism.og/ textfiles/board-062001.html em 20/03/ 2002.

35 LATOUR, B. (1994) op. cit.

36 Id. (2001) p. 232.

* Psicóloga, Mestre em Psicossociologia de Comunidades e Ecologia Social pelo Programa EICOS - Cátedra Unesco de Desenvolvimento Durável, da Universidade Federal do Rio de Janeiro, e doutoranda do Curso de Pós-Graduação em

Desenvolvimento, Agricultura e Sociedade - CPDA, da Universidade Federal Rural do Rio de Janeiro.

Artigo premiado em $1^{\circ}$ lugar - Categoria Externa - do Prêmio Sesc-Senac de Turismo Sustentável, realizado em outubro de 2002.

E-mail: Anacamphora@yahoo.com.br.

Recebido para publicação em 02/03/2004. 